\title{
Resenha
}

\section{Brasilien: Virtudes e limitações de uma tradição de pesquisa}

\author{
Marcelo Lopes de Souza
}

Brasilien: Beiträge zur Wirtschafts- und Sozialgeographie aus über 50 Jahren Brasilien-Forschung, Gerd Kohlhepp. Stuttgart, Franz Steiner Verlag, 2020, 617 pp., ISBN 978-3515124553.

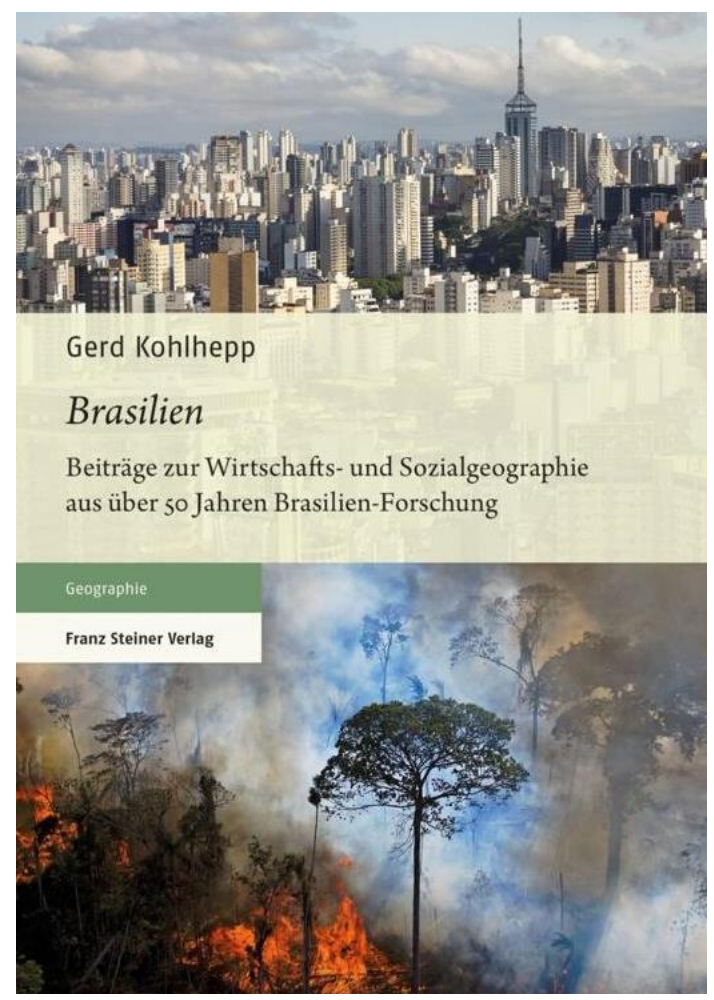

Raríssimos geógrafos brasileiros terão a oportunidade de desfrutar da leitura de Brasilien: Beiträge zur
Wirtschafts- und Sozialgeographie aus über 50 Jahren Brasilien-Forschung (Brasil: Contribuições para a Geografia 
Econômica e Social com base em mais de cinquenta anos de pesquisas sobre o Brasil), livro do geógrafo alemão Gerd Kohlhepp publicado em fins de 2020. A barreira da língua, que já se faz sentir no caso do inglês e ainda mais no do francês, mostra-se quase intransponível em se tratando do idioma alemão. Já vai muito longe a época em que, na própria Geografia - como na Física e em algumas outras áreas -, o alemão era a principal língua de expressão dos cientistas de ponta. A Segunda Guerra Mundial abalou completamente o quadro da "geopolítica da produção e circulação do conhecimento" no mundo, inclusive no que se refere a esse aspecto: não apenas pelo definitivo deslocamento do eixo geoeconômico global para os Estados Unidos, mas também pela crescente supremacia cultural da pop art (especialmente a música e o cinema) estadunidense. A partir da segunda metade do século $X X$, paulatinamente, $O$ inglês tornou-se a nova língua franca do "império" (no sentido de Antonio Negri e Michael Hardt), ou o "latim" dos novos tempos globalizados. A isso

\footnotetext{
${ }^{1} \mathrm{O}$ internacionalmente renomado e respeitado Carl Troll tentou, logo após a guerra, por meio de um longo artigo que foi traduzido para o inglês, persuadir seus colegas de outros países de que o comprometimento da Geografia alemã havia sido um fenômeno restrito a uns poucos casos desviantes, fascinados com a Geopolítica. Não muita gente se deixou convencer. Entre fins dos anos 1960 e início da década seguinte, na esteira do movimento estudantil e do conflito de gerações que sacudiu as universidades da Alemanha e de outros países, jovens começaram a denunciar sistematicamente as
}

se deve acrescentar, não sem a devida ênfase, a desmoralização trazida pelo Holocausto e outros crimes de guerra - e pelo envolvimento direto ou indireto de grande parte dos geógrafos alemães com o regime que perpetrou tudo isso. ${ }^{1}$

Científica, filosófica e artisticamente, ficamos mais pobres. E, no mundo de hoje, um livro como o de Kohlhepp passará, fora de um círculo muito restrito de pesquisadores nos países de fala alemã, provavelmente despercebido. Uma pena, é o mínimo que se pode dizer.

Na Alemanha, assim como na França e na Inglaterra (e também nos Estados Unidos, ainda que em um estilo e com uma temporalidade diferentes), a pesquisa sobre aquilo que, em linguagem de hoje, e utilizando um vocabulário crítico, chamaríamos de a periferia do sistema capitalista, teve origem em interesses ligados ao neocolonialismo e ao imperialismo. Não por acaso, durante décadas existiram cátedras de "Geografia Colonial" nas universidades de tais países. O interessante é que, no caso alemão, a

horrendas ligações entre uma legião de geógrafos alemães dos anos 1930 e 1940 e o Terceiro Reich. O documento Beiträge deutscher Geographieprofessoren zum Faschismus: "Aktivitäten" und "Forschungs"-Ergebnisse (ARBEITSKREIS "GEOGRAPHIE UND FASCHISMUS" DER BUNDESFACHSCHAFTENTAGUNG GEOGRAPHIE, 1997), em particular, demonstra com riqueza de exemplos o papel nada luminoso de nomes de proa como Walter Christaller, Wolfgang Hartke, Erich Obst, Erich Otremba, Siegfried Passarge, Albrecht Penck e o próprio Carl Troll, entre muitos outros . 
Kolonialgeographie existiu e prosperou em um país que teve colônias durante um período relativamente curto, entre a década de 1880 e 1919, com o "sonho colonial" acabando após a derrota na Primeira Guerra Mundial e a assinatura do Tratado de Versalhes. Isso não impediu que geógrafos alemães, entre eles Carl Troll, mantivessem cátedras desse tipo (e com esse nome!) e escrevessem profusamente sobre colônias de outros países, durante o período entreguerras. Após a Segunda Guerra Mundial, a tradição de pesquisa sobre o Outro não europeu e não ocidental (na Geografia, bem como na Antropologia, na Sociologia e na História), persistiu. Cada vez mais depurada e adaptada a um mundo em que as colônias formais estavam fadadas a desaparecer, tais pesquisas sobre outros povos e continentes, em particular sobre os "países tropicais", nem sempre, contudo, escondiam a arrogância eurocêntrica, quando não, em alguns casos, um racismo nu e cru. Sem embargo, diferenças notáveis entre os pesquisadores sempre puderam ser observadas. Essas diferenças, em certos casos, seguramente tinham a ver com a matriz teórica e político-filosófica; todavia, em última análise (e talvez sobretudo), tratava-se de diferenças relativas às sensibilidades, às índoles e aos temperamentos individuais.

Gerd Kohlhepp é herdeiro de uma linhagem intelectual e ético-política especialmente interessante, posto que ela desafia os clichês. Ele foi orientando e assistente de Gottfried Pfeiffer, que também fez pesquisas no Brasil, tendo sido Pfeiffer, por sua vez, orientando e assistente de Leo Waibel, um dos principais nomes da Geografia Agrária alemã dos anos 1930 e 1940. Sem ser um intelectual de esquerda, Waibel era, contudo, um homem de fortes princípios e de uma coragem pessoal ímpar: casado com uma judia, e recusando-se a endossar o regime de Hitler (ele se negara, por exemplo, a fazer a saudação nazista, a qual era exigida dos professores), terminou por ser proibido de ensinar, sendo forçado a deixar a Alemanha. Transferiu-se para os Estados Unidos e, para nossa sorte, veio parar no Brasil em 1946, a convite do Conselho Nacional de Geografia. Ficou por quatro anos entre nós. Antes de deixar o Brasil, pronunciou uma conferência de despedida intitulada "O que aprendi no Brasil" - uma síntese de seus conhecimentos adquiridos em trabalhos de campo, mas também no convívio com assistentes e colegas (WAIBEL, 1950). O tom humilde, sugerido já pelo título, mostra bem os laços de afeto que passaram a existir entre Waibel e o Brasil. Sem nunca perder por completo o ranço eurocêntrico tão evidente em suas obras de juventude (e examinado por RUNKEL, 2013), o geógrafo alemão, um dos maiores de sua geração - a qual foi uma geração de gigantes -, soube relativizar, apesar disso, certos preconceitos que nutrira, 
como quase todos de sua época, contra o Outro "tropical", não branco, não europeu, não ocidental. Poucas vezes vimos ou vemos tamanha grandeza; até mesmo nos dias atuais, em que tantos acadêmicos progressistas do Norte Global facilmente enchem a boca para declarar a própria convicção "decolonial” ou "pós-colonial", isso nem sempre é comum - ou ao menos tão sincero. Essa é a linhagem de que Gerd Kohlhepp descende, e é à luz dela que podemos melhor apreciar as qualidades de sua obra. Quanto aos defeitos (ou, mais exatamente, aos limites), para entendê-los necessitaremos de mais uma camada de contextualização, oferecida no próximo parágrafo.

Nascido em 21 de março de 1940 em Mannheim, Gerd Kohlhepp graduou-se em Geografia em 1962, doutorando-se em 1967 na conceituada Universidade de Heidelberg. A Alemanha pós-Segunda Guerra ainda conheceu um certo florescimento de correntes acadêmicas de esquerda, notadamente a Escola de Frankfurt (ou o que dela restara, depois de tragédias como a de Walter Benjamin ou de exílios que se tornaram permanentes, como o de Herbert Marcuse); não era, porém, nem mesmo a sombra do que havia sido antes da devastação humana causada pelo Terceiro Reich. A Geografia alemã, que nunca chegou a ter em suas fileiras nomes como um Élisée Reclus ou um Piotr Kropotkin, ressentiu-se em especial de um con- servadorismo que persistiu, ainda que em nível moderado, mesmo após a desnazificação gradual que adveio com o fim da guerra e a ocupação pelos Aliados. Como resultado, enquanto jovens geógrafos britânicos e estadunidenses (David Harvey, Richard Peet, William Bunge etc.) e franceses (com destaque para Yves Lacoste) começavam, na virada da década de 1960 para a década de 1970, sob a influência de diversos movimentos sociais (pelos direitos civis dos negros, contra a Guerra do Vietnã, movimento estudantil, contracultura etc.), a protagonizar o que veio a ser conhecido como a "virada crítica" (o radical turn dos geógrafos anglófonos), na Alemanha, em contraste, os abalos sísmicos sentidos na Geografia (como durante o célebre Congresso de Geógrafos Alemães [Geographentag] de Kiel, em 1969) foram relativamente modestos, não tendo deixado marcas tão duradouras ou tão profundas, comparáveis à "Geografia Crítica" anglo-americana e francesa (e, já em fins dos anos 1970 e início dos 1980, também brasileira). Os debates animados por leituras e uma orientação teórica marxistas (o pensamento libertário esteve quase ausente) tiveram, aqui e ali, em algumas universidades e em algumas disciplinas (principalmente na Ciência Política e na Sociologia), expressão relevante; mas nada disso ocorreu na Geografia. Assim como a própria Geografia neopositivista ("quantitativa") tivera pouca reper- 
cussão no país de Goethe, o mesmo se deu com o radical turn. Os geógrafos alemães até protagonizaram alguns acertos de contas com a Geografia clássica (por exemplo, ao criticarem o constructo da Landschaft, em estilo semelhante ao utilizado por Lacoste para levantar objeções contra a "região" lablacheana), mas sem chegarem a bancar uma corrente teórica geográfica de indiscutível conteúdo antiimperialista, socialmente crítica e antissistêmica, nos moldes de seus colegas de outros países. Na Alemanha, com isso, tipicamente, as décadas de 1960, 1970 e 1980 ainda conheceram uma Geografia que até soube se renovar em parte, mas em grande medida mantinha alguns compromissos epistemológicos, teóricos e político-filosóficos herdados do período clássico da disciplina. Para o bem e para o mal, como veremos.

Brasilien é uma coletânea de 23 artigos e ensaios, escritos ao longo de um arco temporal que vai de 1966 (quatro anos após o autor iniciar sua trajetória de pesquisas sobre o Brasil) até 2017. Invariavelmente, o que se percebe, em cada trabalho, é uma combinação de apuro técnico, fundamentado em uma enorme valorização do trabalho de campo, com um olhar aguçado para a detecção de problemas e contradições. Sobre o primeiro aspecto, cabe aqui algo que nunca será demais ressaltar: se a pesquisa empírica necessita ser bem fundamentada teoricamente, não menos importante é a teoria poder ser sistematicamente alimentada por estudos empíricos de detalhe e bem conduzidos - exatamente aquilo que, na Geografia Humana brasileira, vem sendo mais ou menos negligenciado nos últimos quarenta anos. Sobre o segundo aspecto - o olhar aguçado para a detecção de problemas e contradições -, Gerd Kohlhepp nos traz vários artigos em que isso, por assim dizer, dá o tom, ao abordar assuntos como os conflitos de interesse entre agronegócio e agricultura familiar e camponesa, (exemplificado pelo estímulo aos cash crops e aos biocombustíveis em detrimento do apoio às lavouras alimentares); a instrumentalização da colonização da Amazônia como uma "antítese" da reforma agrária pelo Regime Militar (que deu ensejo, aliás, a um dos mais relevantes trabalhos de Kohlhepp); os problemas sociais e ecológicos em torno da construção de grandes usinas hidroelétricas; e assim sucessivamente.

A afeição e a admiração do autor pelo Brasil se notam em muitos lugares, mas em especial na conferência "Brasilien - Schwellenland oder tropische Großmacht des 21. Jahrhunderts?" ("Brasil - País emergente ou grande potência tropical do século XXI?"), proferida na Universidade de Tübingen em 2012. Há aí, porém, como que um excesso de esperança, que se manifesta já nos referenciais conceituais usados. "Schwellenland", palavra sem correspondente 
exato em português, significa algo como "país que está no limiar ou umbral (do desenvolvimento)", podendo ser traduzida como "país emergente"; esta é uma expectativa presente no senso comum, mas que as reflexões mais críticas sobre o "desenvolvimento" já demonstraram ser problemáticas. Quanto a "grande potência tropical", é de se perguntar se uma ideia como a de "grande potência", que com frequência assusta os vizinhos sul-americanos, é a mais frutífera não somente para compreender os processos em curso, mas também para projetar um futuro desejável.

Um tal otimismo, mesmo em 2012 (de 2013 para cá, justamente, o país vem descendo ladeira abaixo, tanto política e institucional quanto economicamente), já seria excessivo; mas esse "excesso" se explica também, ou sobretudo, pelos limites interpretativos derivados da matriz teórico-conceitual e político-filosófica adotada, bastante atenta a gargalos internos ao próprio país, mas com dificuldades para situar esses mesmos gargalos nos marcos da formação do sistema mundial capitalista e do papel que o Brasil aí desempenha - e do qual não irá se livrar facilmente, ainda que houvesse uma sucessão de governos nacionais mais "competentes", socialmente mais sensíveis, menos cleptocráticos etc. (problemas que, aliás, só são plenamente compreensíveis à luz da longue durée da constituição e das mutações, não raro mais aparentes que reais, do capitalismo [semi]periférico brasileiro). Já em um artigo de 1978, sobre o "Entwicklungsmodell" (modelo de desenvolvimento) brasileiro, mesmo sem deixar de perceber e analisar alguns problemas estruturais, o autor parece subestimar um pouco a magnitude dos obstáculos a serem enfrentados e superados. Isso não impediu Kohlhepp, contudo, de salientar questões importantes ou mesmo cruciais, mormente aquelas que mais diretamente dependem de (ou poderiam ser influenciadas por) decisões governamentais e políticas públicas nas escalas nacional, regional/estadual e local/municipal. Ao examinar, em vários artigos e ensaios, os agentes e as margens de manobra que dizem respeito a tais questões, no âmbito do próprio Brasil, o autor exercita uma poderosa imaginação geográfica, brindando-nos com trabalhos pormenorizados, claros e informativos. Cada vez mais, entretanto, precisamente no que diz respeito a margens de manobra para decisões governamentais "soberanas", é de se perguntar o que ainda é possível na era do capitalismo das empresas transnacionais e da globalização, substancialmente mais desafiador em comparação com a época das multinacionais tematizadas pelos teóricos da "dependência" dos anos 1960 e 1970 (cuja presença nos escritos de Kohlhepp se faz notar menos do que teria sido, talvez, desejável; penso, por exemplo, em Ruy Mauro Marini e sua seminal contribuição so- 
bre o "subimperialismo" brasileiro). Os processos de desindustrialização e reprimarização da economia, nítidos há quase três décadas, e que vêm se acelerando, apontam na direção contrária de uma superação da condição (semi)periférica.

O melhor do autor pode ser encontrado, indiscutivelmente, em seus estudos de Geografia Agrária e Geografia Regional; a isso se devem acrescentar algumas belas e inspiradoras incursões no tema da História da Geografia, particularmente da história das pesquisas e do olhar alemães sobre o Brasil, e também em alguns trabalhos de Geografia Regional Histórica, em que sobressai o interesse pela colonização alemã no Brasil meridional (tema de que já se ocupara Leo Waibel, duas gerações antes). Sobre a Geografia Histórica, seja-me permitido registrar que, entre nós, essa vem sendo uma temática crescentemente cultivada nos últimos vinte anos, mas muitas vezes fica a impressão de se estar diante de esforços de caráter eminentemente historiográfico (e o mais das vezes um tanto amadores), em que a espacialidade não vai além de um verniz. Nesse ponto, os trabalhos de Gerd Kohlhepp sobre a presença histórica alemã no Sul do Brasil, ao lado das contribuições de um mestre brasileiro da Geografia Histórica como Mauricio de Almeida Abreu, constituem verdadeiras aulas sobre como não se precisa ou se deve abrir mão do raciocínio espacial, sob pena de cair- mos em uma espécie de limbo epistemológico.

Tirando um delicioso ensaio introdutório sobre a herança deixada por Leo Waibel na pesquisa geográfica alemã sobre o Brasil, Brasilien se divide em quatro grandes partes: "Temas gerais"; "Sudeste e CentroOeste"; "Sul do Brasil"; “Amazônia". Se os trabalhos propriamente de Geografia Regional (histórica ou não), Geografia Agrária e História da Geografia nos trazem Gerd Kohlhepp em sua melhor forma, nem por isso a coletânea escapa de uma certa heterogeneidade qualitativa. A condição de "brasilianista", que Kohlhepp de alguma forma compartilha com outros ilustres pesquisadores estrangeiros, cobra um preço, ao impor que se "deva" escrever sobre muitos e variados assuntos: compreensivelmente, nem todos eles haverão de poder ser cobertos com a mesma originalidade ou a mesma profundidade. Assim é que as incursões de Kohlhepp nos estudos urbanos, bastante pontuais (representadas em Brasilien por um artigo sobre São Paulo e outro, genérico, sobre aspectos geodemográficos e a urbanização), não possuem o mesmo calibre de suas contribuições a outros campos do conhecimento geográfico. Mesmo nesses casos, de qualquer maneira, não estão ausentes interessantes aportes. $O$ estudo mais geral sobre a urbanização, de 1982, contextualiza tal processo à luz de tendências geodemográficas de longo prazo, o que é 
indiscutivelmente útil (principalmente porque Kohlhepp sabe evitar o neomalthusianismo); sua defesa de um planejamento regional que estimule a desconcentração industrial e da urbanização, em particular reforçando o papel das cidades médias, esbarrou, poucos anos depois da publicação do artigo, na retração dos tímidos esforços governamentais nessa direção, mas não deixam, por isso, de fazer sentido. É certo que, aparentemente, o autor depositava, na época, demasiadas esperanças em medidas estatais de planejamento; seja lá como for, essa expectativa estabelece um saudável contraste (do ponto de vista do debate acadêmico) com o lamentável costume da Geografia Urbana brasileira de silenciar sobre essas questões.

O ponto alto do livro e da carreira de Gerd Kohlhepp, creio, são os seus trabalhos sobre os problemas amazônicos. Suas pesquisas sobre a Amazônia começaram nos anos 1970, e não seria exagero algum afirmar que, desde a década de 1980, ele tem figurado, internacionalmente, entre os principais conhecedores da Amazônia e de seus problemas econômicosociais e ecológicos. Juntamente com suas contribuições sobre a questão agrária brasileira, mas de modo ainda mais cristalino, é ao lidar com a temática amazônica que Kohlhepp se nos apresenta como um virtuose em duas coisas que, no Brasil, desgraçadamente, minguaram até quase desaparecer da agenda da Geografia Humana a partir da década de 1980: a capacidade de integrar consistentemente (na esteira da formulação de claros problemas de pesquisa) as dimensões social e ecológica (geobiofísica) da realidade; e a competência para proceder a uma tal integração em escala regional, o que depreende uma significativa habilidade para operar sínteses e resguardar uma visão de conjunto. Outra característica marcante é a preocupação do autor em ir além do diagnóstico e da análise, aventurando-se (cautelosamente) nos prognósticos e na construção de cenários e, por fim, na discussão de alternativas e na formulação de recomendações. Não é preciso concordar sempre ou inteiramente com as avaliações e as sugestões de Kohlhepp para salientar o contraste entre essa postura, ousada mesmo quando comedida (e comedimento é, diplomaticamente, um traço constante de suas contribuições quanto $a$ isso), e a negligência que muitos geógrafos brasileiros revelam no tocante a debater caminhos e estratégias de superação dos problemas (para além, por óbvio, de clamores vagos e arroubos retóricos a respeito das necessárias mudanças sócio-espaciais profundas).

Antes de concluir esta resenha, um último aspecto merece ser devidamente ressaltado. Não são poucos os geógrafos alemães, inclusive de gerações posteriores à de Kohlhepp, que vieram e têm vindo ao Brasil em busca de um objeto de estudo, mas não (ou 
apenas muito limitada e instrumentalmente) de parceiros e interlocutores. Não foi assim com Gerd Kohlhepp. Sua preocupação em dialogar com os brasileiros sempre foi muito grande, assim como seu interesse em ajudar a formar e orientar pesquisadores e em fomentar intercâmbios formais com instituições brasileiras. Sua matriz teórica, infelizmente, não facilitou uma maior penetração de sua mensagem não apenas em face da discrepância político-filosófica com a Geografia crítica de figurino marxista, hegemônica no Brasil, mas também devido ao choque entre uma Geografia que se recusava a jogar fora o interesse pelos processos geobiofísicos e uma outra que, até pouco tempo atrás, tinha por meta a transformação da disciplina em uma "ciência social pura". É uma ironia que hoje em dia, passada a pior fase da iconoclastia "anticlássica" e em meio a uma revalorização da transversalidade epistemológica intradisciplinar - da qual AMBIENTES é um dos exemplos mais notáveis e eloquentes -, traços fundamentais da mensagem de Kohlhepp possam ser melhor compreendidos e aceitos, ao mesmo tempo em que escritos tão importantes, na sua maior parte sem tradução para o português, tenham, provavelmente, de permanecer desconhecidos. Seja lá como for, Kohlhepp fez muitos amigos no Brasil (entre eles Orlando Valverde, que o influenciou, aliás, no que se refere a despertar o seu interesse pela Amazônia), assim como teve também alunos e orientandos brasileiros (entre os quais me incluo), angariando um número considerável de interlocutores.

Ao final da conferência de despedida "O que aprendi no Brasil", de 1950, Leo Waibel endereça palavras de encorajamento ao Conselho Nacional de Geografia: "Viva! Cresça! Floresça!". É fácil ver que as sementes lançadas por Waibel germinaram, e que Gerd Kohlhepp (e Gottfried Pfeiffer antes dele) soube ser um jardineiro zeloso e eficaz, adubando o solo e cuidando do legado de Waibel, além de plantar suas próprias sementes. Brasilien é o testemunho de uma carreira de mais de meio século devotada a uma Geografia consciente do valor da pesquisa empírica de detalhe, da importância do diálogo (entre "Geografia Humana" e "Geografia Física", mas também para fora da Geografia e para além da própria ciência, incorporando os saberes de outros atores sociais), da relevância das ferramentas da Geografia (como a linguagem cartográfica) e, last but not least, da utilidade científica e da necessidade ética de se buscar a cooperação com o Outro, com os brasileiros (nas universidades e fora delas). Ainda que importem as eventuais discordâncias com o autor, elas empalidecem, neste momento, diante de tamanhas realizações, alcançadas sobre os fundamentos da boa-fé, da honestidade intelectual, do esforço, do talento geográfico e da tolerância intercultural. $\mathrm{O}$ 
menino que nasceu em Mannheim no alvorecer da Segunda Guerra Mundial, quando as primeiras bombas dos Aliados já estavam caindo em sua cidade natal, viveu o suficiente para fortalecer, com trabalho e amizade, várias pontes: dentro da própria Geografia e entre a ciência e diversos agentes sociais, mas também entre dois continentes e entre dois países. A ele, o nosso Dankeschön.

\section{Referências}

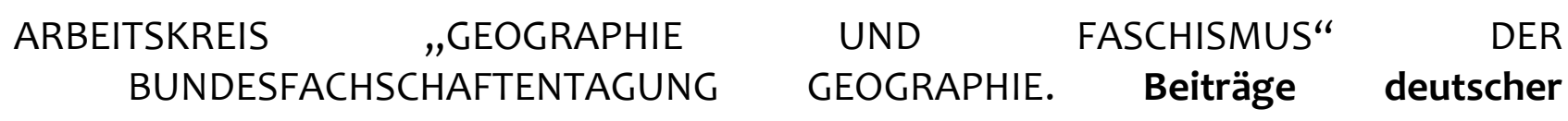
Geographieprofessoren zum Faschismus: "Aktivitäten" und "Forschungs"Ergebnisse. Colônia e Bonn: mimeo, 1997.

RUNKEL, Simon. Die „geographical imaginations“ des jungen Leo Waibel im Kontext der geographischen Disziplin zu Beginn des 20. Jahrhunderts am Beispiel der Monographie „Urwald, Veld, Wüste“. In: SCHENK, Winfried (org.): Leo Waibel Zur Rezeption seiner Arbeiten in Brasilien, Afrika und Deutschland. Bergisch Gladbach: E. Ferger Verlag, 2013, pp. 62-77.

WAIBEL, Leo. O que aprendi no Brasil. Revista Brasileira de Geografia (IBGE, Rio de Janeiro), v. 12, $n^{\circ} 3$, (1970 [1959]), pp. 419-428.

Marcelo Lopes de Souza é Professor Titular do Departamento de Geografia da Universidade Federal do Rio de Janeiro (UFRJ) e pesquisador do CNPq. E-mail: mlopesdesouza@ufrj.br 